\title{
Large-scale survey of Chinese precollege students' epistemological beliefs about physics: A progression or a regression?
}

\author{
Ping Zhang ${ }^{1, *}$ and Lin Ding ${ }^{2, \dagger}$ \\ ${ }^{1}$ Department of Physics, Beijing Normal University, Beijing, 100875, People's Republic of China \\ ${ }^{2}$ Department of Teaching and Learning, The Ohio State University, Columbus, Ohio 43210, USA
}

(Received 10 October 2012; published 1 April 2013)

\begin{abstract}
This paper reports a cross-grade comparative study of Chinese precollege students' epistemological beliefs about physics by using the Colorado Learning Attitudes Survey about Sciences (CLASS). Our students of interest are middle and high schoolers taking traditional lecture-based physics as a mandatory science course each year from the 8th grade to the 12th grade in China. The original CLASS was translated into Mandarin through a rigorous transadaption process, and then it was administered as a pencil-and-paper in-class survey to a total of 1318 students across all the five grade levels (8-12). Our results showed that although in general student epistemological beliefs became less expertlike after receiving more years of traditional instruction (a trend consistent with what was reported in the previous literature), the cross-grade change was not a monotonous decrease. Instead, students at grades 9 and 12 showed a slight positive shift in their beliefs measured by CLASS. Particularly, when compared to the 8th graders, students at the 9th grade demonstrated a significant increase in their views about the conceptual nature of physics and problem-solving sophistication. We hypothesize that both pedagogical and nonpedagogical factors may have contributed to these positive changes. Our results cast light on the complex nature of the relationship between formal instruction and student epistemological beliefs.
\end{abstract}

DOI: 10.1103/PhysRevSTPER.9.010110

PACS numbers: 01.40.Fk, 01.40.ek, 01.40.G-

\section{INTRODUCTION}

In the past two decades the physics education research community has developed a growing interest in students' epistemological ideas about physics-students' beliefs about knowledge and learning [1-6]. A primary reason for this emergent interest lies in a compendium of research findings suggesting that students' beliefs about physics can exert a direct and significant influence on their learning $[1,2,7,8]$. Students who view physics as a large collection of disconnected facts or formulas being passively dispensed from experts and hence irrelevant to their daily lives are likely to study this subject by using rote memorization and algorithmic approaches. Conversely, those who view physics as centered on a few governing fundamental principles and consider learning as making sense of these principles through connections to the physical world are more comfortable with building a deeper conceptual understanding without excessively relying on formalism.

Researchers have conducted both case studies and surveys to investigate students' beliefs about the nature of physics. Hammer followed a few college students taking introductory physics through an entire semester $[1,2]$. By

\footnotetext{
*zhangping@bnu.edu.cn

†ding.65@osu.edu
}

Published by the American Physical Society under the terms of the Creative Commons Attribution 3.0 License. Further distribution of this work must maintain attribution to the author(s) and the published article's title, journal citation, and DOI. regular interviews he found that students' beliefs about physics can be characterized along three dimensions: coherence (whether physics knowledge is coherently structured or fragmented), concept (whether learning physics is about manipulation of formulas or gaining conceptual understanding), and independence (whether physics knowledge is transmitted from experts or acquired through learners' own sense making). Using the three-dimensional framework, Hammer demonstrated that students' learning difficulties largely stemmed from their beliefs about what physics is and how it should be learned [2]. Lising and Elby conducted an in-depth case analysis of one student in an introductory physics course [4]. They looked into the student's classroom activities, written work, and interviews, and convincingly presented that it was the student's epistemological stance that prevented her from reconciling between daily-life intuitive thinking and formal reasoning; hence causing noticeable difficulties in her studying physics. Lising and Elby then concluded that student epistemology has a causal influence on learning [4].

Besides those in-depth case studies, surveys that measure student beliefs about physics also have been developed for use in large-scale quantitative studies. These include the Colorado Learning Attitudes about Science Survey (CLASS) [9], the Epistemological Beliefs Assessment for Physical Science (EBAPS) [10], the Maryland Physics Expectation Survey (MPEX) [11], and the Views about Science Survey (VASS) [12]. Among them, CLASS perhaps is the most commonly used survey. It was purposely designed to be suitable for students at all 
levels and not tied to specific courses [9]. The language used in CLASS was also carefully phrased to minimize misinterpretation so that both experts and students-even those who never studied physics - can understand the questions [9].

Studies using these surveys to gauge epistemology have consistently shown that students' views about physics often become more novicelike after one or two semesters of formal instruction $[9,11,13,14]$. Many traditional and reformed physics curricula alike failed to promote expertlike beliefs among students $[9,11,13,14]$. Abd-El-Khalick and Lederman pointed out that student epistemological beliefs are cognitive (not affective) in nature and are best cultivated in science content courses that explicitly and reflectively discuss the nature of science [15-17]. Otero and Gray studied the effect of two inquiry-based curricula, namely Physics and Every Thinking (PST) and Physical Science and Everyday Thinking (PSET), on student epistemological beliefs [18]. These two curricula followed an explicit and reflective instructional approach to the nature of science and the nature of learning science $[19,20]$. After receiving a semester of PST and PSET instruction, students showed a statistically significant increase in their beliefs about the nature of physics, measured by the CLASS [18]. Brewe et al. used similar approaches in modeling instruction (MI) to engage students in scientific practices of model building, evaluation, and deployment [21,22]. They too found that students gained a positive change in CLASS after each semester throughout a two-semester sequence [23]. Redish and Hammer designed a new physics course for biology majors with an explicit focus on student epistemological resources [24]. When measured by the MPEX, students who took this course revealed an expertlike shift in their beliefs about physics [24]. Lindsey et al. studied the effect of the Physics by Inquiry curriculum (PBI) [25] on students' epistemological beliefs [26]. They found that although there was no explicit instruction on the nature of physics in PBI, the fact that students were given opportunities to participate in and reflect on the knowledge generation processes in class promoted their favorable views about physics, as measured by CLASS [26].

While the above studies have elucidated some important relational mechanisms between instruction, epistemology, and learning in the domain of physics. Nearly all of them were conducted with college students and postgraduates in the context of American or European higher institutions $[27,28]$. Since physics is not a required course for precollege students in the U.S., many students either choose not to take it or are not offered such courses in their schools. As a result, there is limited research on early-age students' epistemological beliefs about physics. Moreover, little is known about students in other nations and particularly in Asian countries. In fact, to the best of our knowledge, there are no empirical studies using CLASS to investigate student beliefs about physics in Asian countries. Given the fact that physics is a required course in China starting from the 8th grade throughout the 12th grade spanning both middle school (7th-9th grades) and high school levels (10th-12th grades), it provides us a unique opportunity to study how Chinese early-age students taking physics as a compulsory course view what this subject is and how it should be learned.

In this paper, we use CLASS to measure Chinese students' beliefs about the nature of physics. Specifically, we seek to answer the following research questions:

(1) How do Chinese middle school and high school students perform on CLASS?

(2) What are the cross-grade patterns in student epistemological beliefs measured by CLASS?

(3) How do the patterns identified in this study compare to what has been reported in the literature?

(4) What instructional and research implications can we draw from this study?

In what follows, we report the study methodology in Sec. II, followed by data analysis and findings in Sec. III. Discussions and conclusions are presented in Secs. IV and V respectively.

\section{METHODOLOGY}

\section{A. Translation of CLASS}

We chose to use CLASS for investigating students' beliefs about the nature of physics mainly because this survey is not course specific and suitable for students taking any level of physics. In this study, CLASS was translated into Mandarin for use with Chinese students. A rigorous translation process called "transadaptation" was used to maximally maintain the fidelity of the original survey $[29,30]$. First, two researchers-author L. D. and a nonphysics science education researcher fluent in both languages-independently translated CLASS into Mandarin. The two translated versions were scrutinized by author P.Z. who then revised them into a single version that was fully agreed upon by all the three researchers. Next, another bilingual researcher who did not know CLASS at that time translated the Mandarin CLASS back to English. This backtranslated CLASS was then carefully compared to the original CLASS by two researchers (an English native speaker and a bilingual researcher) to further refine our translation. At this stage, we also researched relevant literature and paid particular attention to the previously reported problematic items [31]. For example, we carefully worded item 6 (Knowledge in physics consists of many disconnected topics) and item 21 [if I don't remember a particular equation needed to solve a problem on an exam, there's nothing much I can do (legally) to come up with it], so that it appeared evident in our translation that the word "disconnected" in item 6 referred to knowledge within physics (not physics in 
relation with other subjects) and the word "it" in item 21 referred to "equation" (not "solutions to a problem") [31].

We also used the Mandarin CLASS for one-on-one interviews with nine Chinese students at various grade levels to check whether or not their interpretation matched the intended meaning of the original CLASS items [32]. During the interviews each student was asked to rephrase the meaning of all CLASS items and to provide explanations for their answers. No misinterpretation or misalignment between their choices and explanations was found. Additionally, we tried out our Mandarin CLASS as a written survey with a total of 244 students at all grades and explicitly asked them to leave blank for items whose meaning they were uncertain about. Of the total 10248 person-item cases ( 244 persons $\times 42$ items), there were only 48 missing answers (accounting for less than $0.5 \%$ of all possible occurrences). Among them, item 27 had the highest frequency of missing four students' responses, and all others missed either one or two responses. Our reexamination of the translated item 27 (it is important for the government to approve new scientific ideas before they can be widely accepted) revealed no particular reason for confusion about its literal meaning, except that these four students (out of a total of 244) perhaps were unsure if government should truly be responsible for the endorsement of scientific knowledge.

TABLE I. Content and sequence of Chinese middle and high school physics.

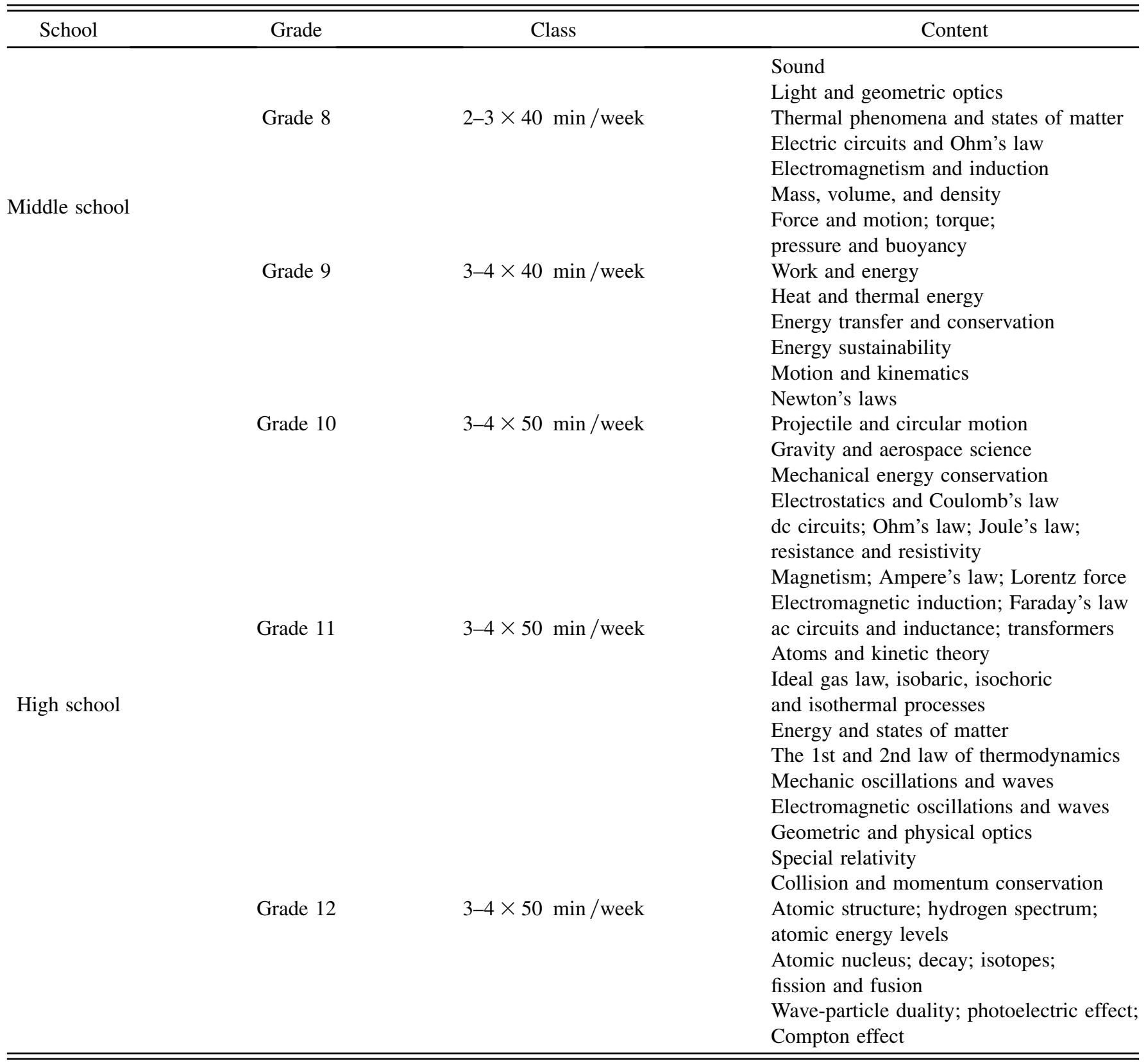


Fine-grained refinement of the CLASS translation continued. Through rounds of careful discussions between the authors and with a group of bilingual Chinese physicists, as well as through personal communications with the CLASS authors [33], we finalized our translation. This final version was agreed upon by all the bilingual researchers involved in the translation process.

\section{B. Student participants and background}

The student population of interest in this study is Chinese middle and high schoolers taking physics as a separate science course. To reduce possible confounding variations between different institutions, we deliberately chose both middle and high schools that were at the same level in terms of their ranking. Since students attending middle schools of a certain ranking usually will be admitted into high schools of a similar ranking, our choice of participating schools maintained the comparability between the middle and high school student populations. In our study, all the participating schools were ranked in the top tiers and considered as competitive in preparing students for higher level education. Invariably, for each chosen middle school, students from both grade 8 and grade 9 were recruited. Similarly, for each participating high school, students at all levels of grades 10-12 were drawn to take the CLASS.

In China, students are required to take physics each year from grade 8 through grade 12 by following a standard physics curriculum mandated by the Department of Education. During this period, there are two learning cycles taking place. One is in middle school at grade 8 and grade 9; students are introduced to basic physics concepts and learn to use them to describe, explain, and predict common physical phenomena. Topics covered in this cycle are conceptually oriented and are fairly comprehensive, including mechanics, electricity and magnetism, thermal physics, waves, sound, and optics. Details on the content and sequence are listed in Table I. The physics classes students attend are typical traditional lectures, scheduled to convene 2-3 times for 8th graders and 3-4 times for 9th graders per week with each lasting 40 minutes. These lectures are taught through direct instruction with a primary focus on content learning and drill and practice. Since student labs also are a required component of physics education, once every few weeks a class is devoted entirely to students experimenting with hands-on activities. These labs generally follow cookbooklike approaches, and the topics are mandated by the national physics standards. As seen, both the lectures and labs are traditional in the sense that no specific attention is devoted explicitly to the cultivation of student epistemic growth.

The second learning cycle occurs in high school from grade 10 to grade 12. During this period, students learn to use mathematics to express physics ideas, an approach similar to algebra-based introductory physics. Topics
TABLE II. Participating student composition.

\begin{tabular}{lrc}
\hline \hline \multicolumn{1}{c}{ School } & Grade & Number of Students \\
\hline \multirow{2}{*}{ Middle school $(N=521)$} & 8 th & 220 \\
& 9 th & 301 \\
High school $(N=797)$ & 10 th & 289 \\
& 11 th & 231 \\
Total & 12 th & 277 \\
\hline \hline
\end{tabular}

covered in the second cycle are the same as those in the first cycle but are discussed in more depth and involve more mathematical calculations (see Table I). As seen, high school physics follows more closely the traditional algebra-based introductory physics in both content and sequence. Similar to the middle school class format, the high school physics classes are traditional lectures that meet 3-4 times a week with each lasting 50 minutes. Student labs following standard topics and formats are occasionally run once every few weeks to allow student hands-on experiences.

It is worth noting that in China the annual High School Entrance Examination administered at the end of grade 9 and the University Entrance Examination administered at the end of grade 12 are two significant events considered by all students as a deciding moment in their lives. Results of these examinations-which include physics as an independent subject test-determine whether each student is qualified to continue their education and if so which school they go to. To best prepare students for these competitive examinations, physics teachers often manage to go through the entire sequence in approximately 1.5 years for the middle school cycle and 2 years for the high school cycle, leaving at least a half year for review and rehearsal.

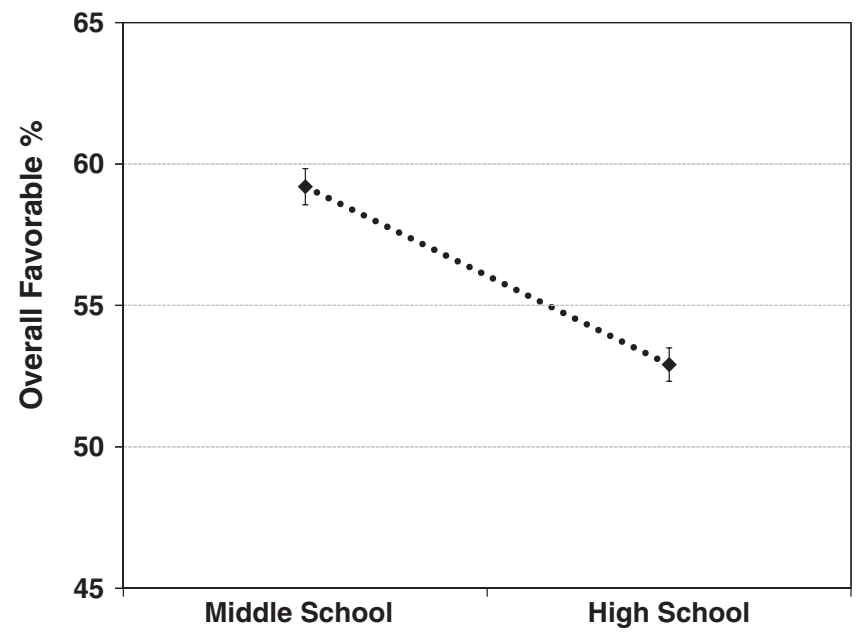

FIG. 1 (color online). Overall favorable percentages on CLASS for middle and high school students. Error bars indicate standard errors. 
TABLE III. Middle school and high school students' favorable percentages on eight CLASS categories.

\begin{tabular}{|c|c|c|c|}
\hline CLASS categories & $\begin{array}{l}\text { Average favorable } \\
\text { Middle school }\end{array}$ & $\begin{array}{l}\text { standard error) } \\
\text { High school }\end{array}$ & $t$ test \\
\hline Real world connection & $76.2 \pm 1.2$ & $64.0 \pm 1.2$ & $t=7.28 p<0.0001$ \\
\hline Personal interest & $59.1 \pm 1.1$ & $47.5 \pm 0.9$ & $t=8.04 p<0.0001$ \\
\hline Senses making/effort & $68.6 \pm 1.0$ & $59.2 \pm 0.9$ & $t=7.08 p<0.0001$ \\
\hline Conceptual understanding & $65.0 \pm 1.0$ & $57.9 \pm 0.9$ & $t=5.43 p<0.0001$ \\
\hline $\begin{array}{l}\text { Applied conceptual } \\
\text { understanding }\end{array}$ & $48.2 \pm 1.0$ & $44.2 \pm 0.8$ & $t=3.11 p=0.0019$ \\
\hline PS general & $67.5 \pm 1.0$ & $57.8 \pm 0.8$ & $t=7.54 p<0.0001$ \\
\hline PS confidence & $68.2 \pm 1.2$ & $57.4 \pm 1.1$ & $t=6.58 p<0.0001$ \\
\hline PS sophistication & $52.5 \pm 1.1$ & $43.3 \pm 1.0$ & $t=6.05 p<0.0001$ \\
\hline
\end{tabular}

\section{CLASS administration}

We administered the Mandarin CLASS to 1318 middle and high school students from 32 classes of eight schools in four Chinese provinces. Among them, 521 students are middle schoolers and 797 are high schoolers. Table II shows the detailed student composition at each grade. The CLASS was given as an in-class paper-and-pencil survey at the midpoint of the autumn semester of 2011, around the 10th week of a 20-week term. Students were given a maximum of 20 minutes to complete the survey and were told to provide their honest responses. No incentives or penalties were offered [34]. Student responses were collected, recorded, and then analyzed.

\section{DATA ANALYSIS AND RESULTS}

We followed the original CLASS scoring schemes to analyze student favorable responses-responses that match experts' views about physics and learning physics. Since CLASS contains eight categories, we analyzed students' percentages of favorable responses for each category as well as for the overall survey. These eight categories are personal interest, real world connection, problem solving general, problem solving confidence, problem solving sophistication, sense making/effort, conceptual understanding, and applied conceptual understanding.

\section{A. Middle school and high school comparisons}

Figure 1 shows the overall favorable percentages on CLASS for both middle school (average $=59.2 \% \pm$ $0.6 \%$ standard error) and high school students (average $=$ $52.9 \% \pm 0.6 \%$ standard error). According to the literature [9], the typical overall CLASS pretest score for U.S. college students enrolled in introductory physics is $57 \%-62 \%$, similar to what we found for our middle schoolers but noticeably higher than that of the Chinese high schoolers.

As seen in Fig. 1, the middle school students displayed more expertlike beliefs than did high school students, and the difference between them was statistically significant $[t(1316)=7.27, p<0.0001$, ES $($ effect size $)=0.4] .{ }^{1} \mathrm{~A}$ further analysis, as seen in Table III, shows that this pattern persisted across all the eight categories, and for each category the difference between the middle and high schoolers was statistically significant (for all $p<0.002$ ). This result seems quite consistent with what was reported in the previous literature; that is, the more traditional instruction students receive, the less expertlike epistemological beliefs they possess. However, this conclusion was derived mainly from comparisons across one or two semesters of physics instruction. In order to see if our results conform to this pattern, we need to conduct cross-grade comparisons, a finer grain-sized analysis.

\section{B. Cross-grade comparisons}

Figure 2 shows the overall favorable percentages on CLASS across all the five grades. Evident from Fig. 2 are two significant drops in the overall favorable percentages at grades 9-10 $[t(588)=3.02, p=0.003, \mathrm{ES}=$ $0.25]$ and grades $10-11[t(518)=3.60, p=0.0004$, $\mathrm{ES}=0.32]$. Given the prior relevant literature on CLASS which consistently showed that student epistemological ideas about physics became less expertlike after one or two semesters of formal instruction, it is not surprising to see the decreases.

Interestingly, however, students' epistemological beliefs about physics (measured by overall CLASS scores) did not monotonously decrease across the grade levels as initially projected. Instead, there were two slight positive shifts (although not statistically significant) at grade 9 and grade 12 , respectively.

We also conducted cross-grade comparisons for each of the eight CLASS categories (see Fig. 3). Given the results

\footnotetext{
${ }^{1}$ Effect size for two independent samples is calculated as follows: $\mathrm{ES}=\left(M_{1}-M_{2}\right) / S$, where $M_{1}$ and $M_{2}$ are means for the two samples, respectively, and $S$ is pooled standard deviation; see Ref. [35] for details.
} 


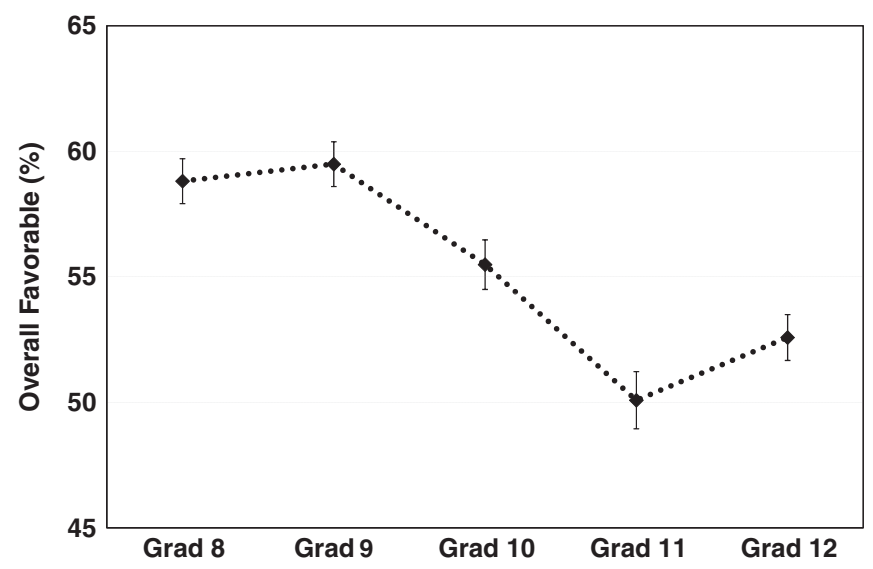

FIG. 2 (color online). Student overall favorable percentages on CLASS across grade levels.

shown in Fig. 3, it is now clear that the slight increase in the 9th graders' overall CLASS scores (cf. Fig. 2) was due to an increase in three categories: "conceptual understanding," "applied conceptual understanding," and "problem solving sophistication." In all three cases, the increase was statistically significant [CU: $t(519)=3.86, p=0.0001$, $\mathrm{ES}=0.34$; applied CU: $t(519)=5.06, p<0.0001, \mathrm{ES}=$ 0.45 ; PS sophistication: $t(519)=2.69, p=0.0073, \mathrm{ES}=$ 0.24]. Conversely, the change in all the other categories between grades 8 and 9 was negative but all insignificant (for all $p>0.07$ ).

Between grades 11 and 12, the shift in most categories was positive and insignificant (for all $p>0.08$ ). Only for the two categories of "real world connection" and "personal interest," student favorable responses revealed a slight decrease; but the decrease was also insignificant (for both $p>0.99$ ).

As for the shifts from grade 9 to grade 10 and from grade 10 to grade 11 , there were consistent decreases for all the eight categories, and all of them were statistically significant (for all $p<0.03$ ). These results were congruent with the significant drops in student overall CLASS performance at these grade levels (cf. Fig. 1).

\section{DISCUSSION}

The above results provide some interesting perspectives for us to reexamine the relations between physics instruction and student epistemology beliefs. Previous literature has repeatedly shown that after receiving 1 or 2 semesters of traditional physics instruction, students' beliefs about the subject (measured by CLASS or other similar surveys) would become notably more novicelike $[9,11,13,14]$. In this study, we looked into middle and high school students' CLASS performances at various grade levels and found that although the general trend emerging from our results conformed to what was reported in the literature, there were some exceptions.
One was the slight positive (but insignificant) shift from grade 8 to grade 9 (cf. Figs. 2). Note that the physics classes students attended in middle school were lecture based, containing no explicit instruction on the nature of physics or activities that engaged students in reflective thinking of authentic scientific practices. That said, the topics introduced at the 8th grade were mostly conceptual in nature and involved little mathematics. Also, the topics did not follow the typical introductory physics sequence. Rather than starting with mechanics, middle school physics first introduced sound, optics, and thermal phenomena, topics that were familiar and appealed to first-year physics learners [36] (see Table I). It is possible that the content and sequence with the appropriate level of difficulty had neutralized the undesirable effects of traditional instruction on student epistemological beliefs. Consequently, after receiving a year or so of formal instruction the 9th graders did not show noticeable declines in their overall views about physics; instead their views related to "conceptual understanding," "applied conceptual understanding," and "problem-solving sophistication" became more expertlike with a statistical significance. Also note the fact that the 9th graders were about to take the competitive High School Entrance Examination at the end of their academic year. Presumably, when facing high-stakes tests, students would be more likely to resort to surface-level learning and hence become less expertlike in their views about the nature of physics. In our study, this potentially negative effect may have been offset by the aforementioned positive effects. Since our survey was conducted in the middle of a fall semester (roughly six months before the annual HighSchool Entrance Examination at the end of the academic year), students perhaps had yet experienced immediately imminent pressure. Therefore, it is likely that the effect of high-stakes test was relatively small in this case. From an alternative perspective, this may also suggest that attitudinal survey results-like those of conceptual assessmentscan be a function of time [34].

The other exception in our results that differed from those documented in the previous literature was the slight positive shift from grade 11 to grade 12 (Figs. 2 and 3). Here, the lowest level of student epistemological beliefs at grade 11 was not a surprise. As mentioned before, physics instruction at the high school level involved more use of mathematical formalism with increasing difficulty. Besides, many high school teachers increased the teaching pace and crammed what was meant for three years of instruction into two years. So it is conceivable that students had little time to digest and internalize all the materials. As a result, their views about physics degraded to the least expertlike level at grade 11. However, what was worth noting is the small rebound at grade 12 . Recall students at this grade had just finished learning all materials and started a grand final review. Perhaps it was because of this review opportunity, minus the overwhelming pressure of 


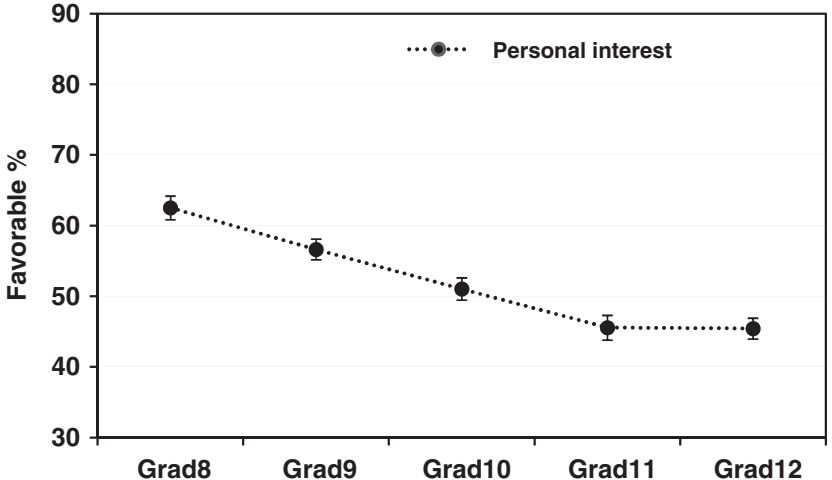

(a)

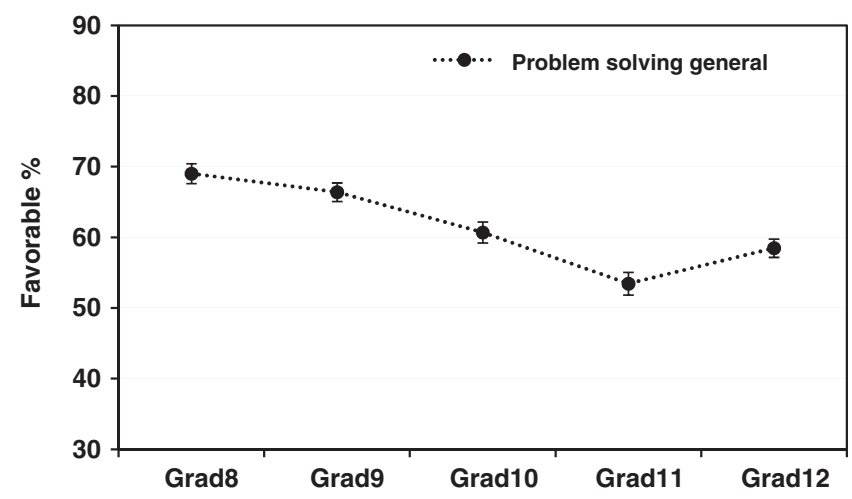

(c)

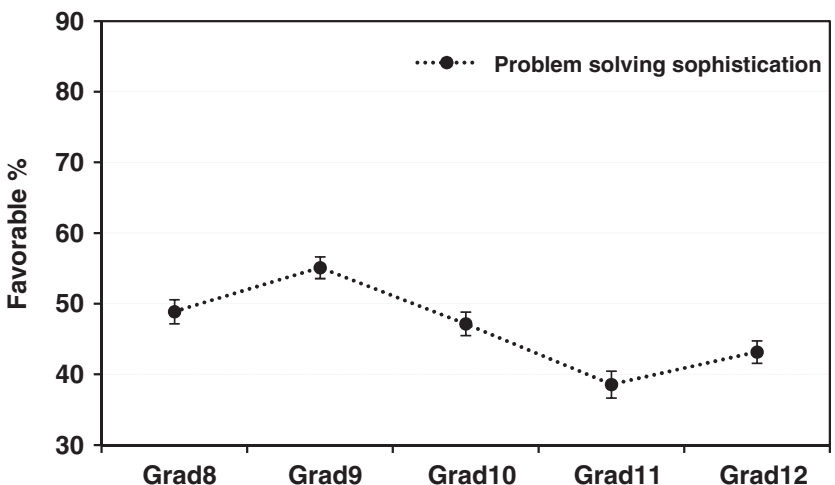

(e)

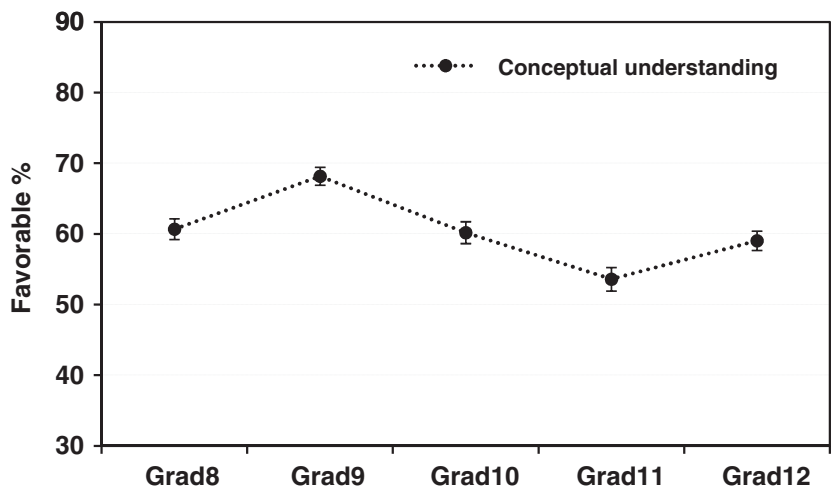

(g)

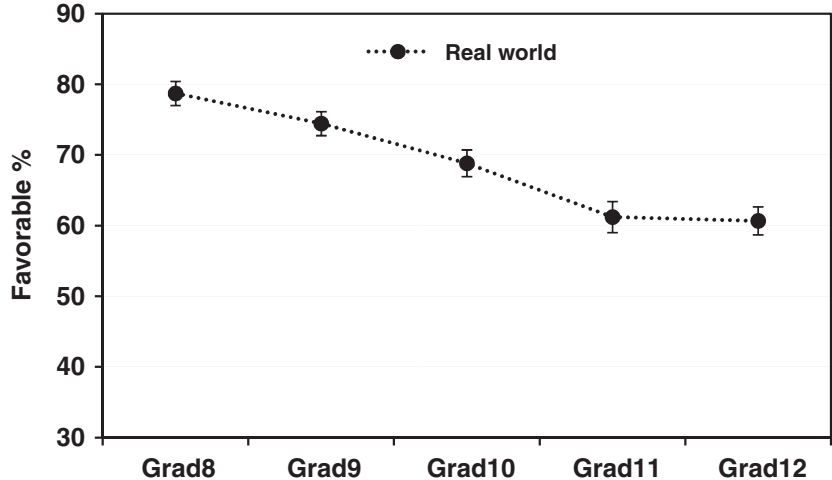

(b)

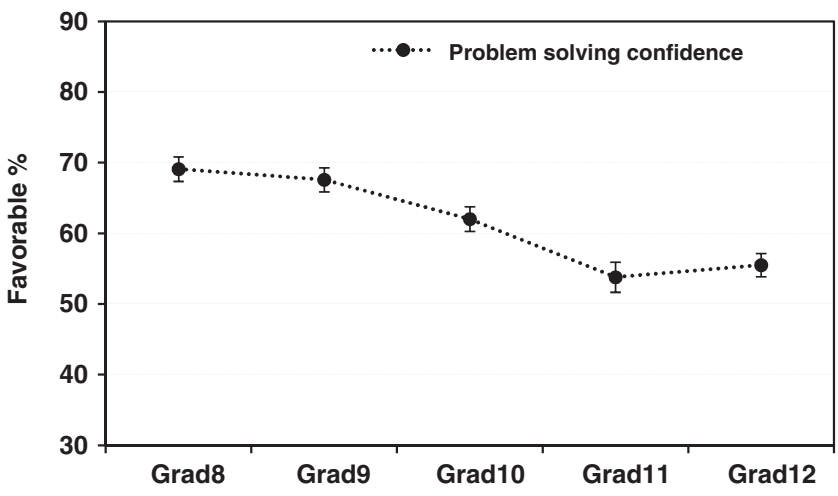

(d)

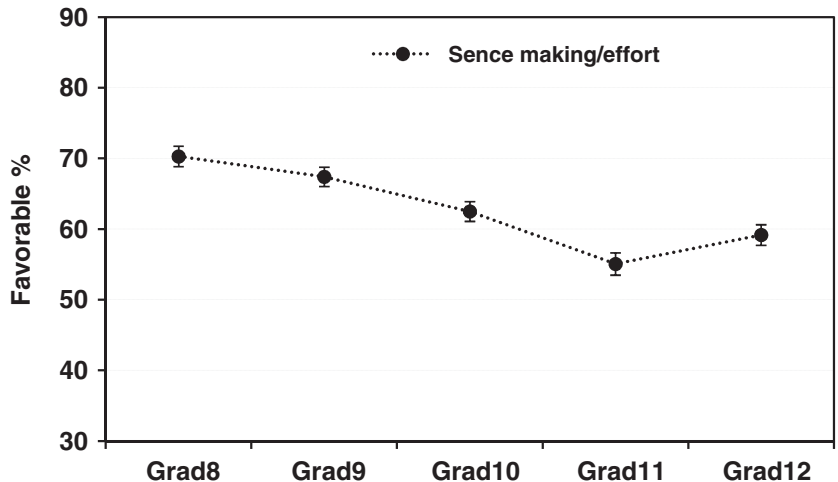

(f)

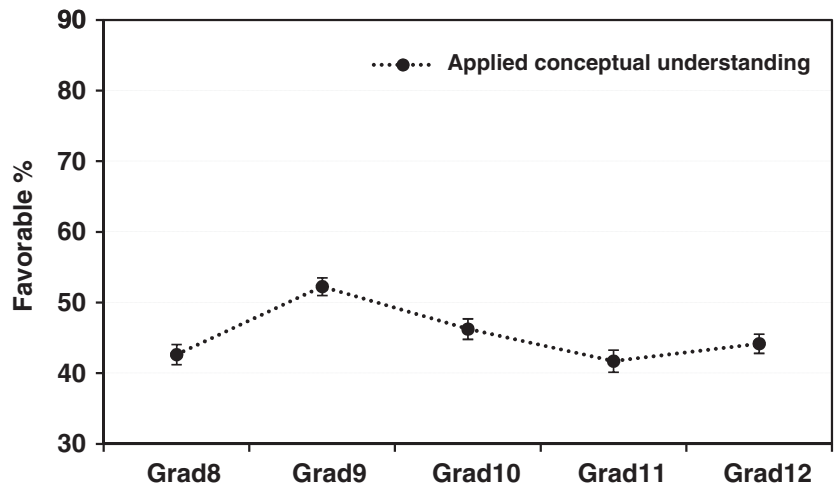

(h)

FIG. 3 (color online). Student favorable percentages on eight CLASS categories across grade levels: (a) personal interest; (b) real world connection; (c) problem solving general; (d) problem solving confidence; (e) problem solving sophistication; (f) sense making; (g) conceptual understanding; and (h) applied conceptual understanding. 
cramming new material, that students finally reached a turning point and started to develop more favorable views about physics. This may suggest that developing a favorable epistemology requires students to assimilate and accommodate understandings about the nature of physics through a constant building and rebuilding of their own views, much like building and rebuilding their own ideas about physics content knowledge. It takes time, effort, iteration, and maybe even some regression along the way. As with the 9th graders, students at grade 12 were also facing a rigid competition in their soon-to-take University Entrance Examination at the end of the academic year. Although this externally imposed high-stakes test by itself may produce a negative impact on student epistemology, its effect perhaps was relatively small and counterbalanced by the review opportunity that allowed students to relearn and digest the subject matter.

These results suggest that the relationship between physics instruction and student epistemological beliefs is rather complex and may be mediated by a number of nonpedagogically related factors, such as content, sequence, teaching pace, review opportunities, and external stimuli. Although our study was not designed to explicate these mediating factors, the emerging results highlighted the multifaceted nature of this topic and beg for future empirical studies along this line.

In particular, future studies that draw on multiple approaches to look into precollege students' epistemological views about physics can be useful. One possible direction is to conduct small-scale case studies with Chinese students and/or physics teachers to elucidate some key factors that underlie the above findings. As a matter of fact, prior to the study we had some in-depth communications with two experienced Chinese middle school teachers who had taught physics at both grades 8 and 9. They were asked to predict what the study results would be and why they thought the results would be such. Both teachers replied that an early curiosity in the subject matter among the 8th and 9th graders would sustain students' positive views about physics, and that the increasingly greater levels of difficulty in new concepts probably would lead to a subsequent decrease in students learning attitudes toward physics. We also had one-on-one interviews with three 12th graders regarding their views about learning physics. All three students complained that the learning pace at grades 10 and 11 was too fast to allow an adequate digestion of learned materials. But they all agreed that the fact grade 12 was mostly devoted to reviewing (and perhaps relearning) those previously taught materials was a tremendous help in their understanding the subject matter at a deeper level. Although more systematic interviews and analyses are needed, the preliminary information extracted from non-written-test contexts serves an additional confirming source for our survey results.

A final caveat worth noting is the unique design of our study; that is, we took a snapshot of students' epistemological beliefs measured by CLASS across different grade levels at approximately the same time. Ideally, a longitudinal study that follows the same cohort of students for an entire period of five years would be preferred. However, given the fairly broad sampling of our data collected from a number of different locations, a cross-sectional measurement like the one in our study can provide a good approximation to longitudinal results [28]. To that end, the results of our study hold values for understanding the trend of how student epistemological beliefs progress (or regress) during their early years of physics learning at the middle and high school levels. Future research in longitudinal studies focusing on a smaller group of students perhaps will be a useful approach to this topic.

\section{SUMMARY AND CONCLUSIONS}

We used CLASS to study Chinese middle school and high school students' epistemological beliefs about physics. The original CLASS was translated into Mandarin through a rigorous "transadaption" process. A total of 1318 students across five grade levels from 8th to 12th grade completed the pencil-and-paper version of the Mandarin CLASS. Results showed that in general students who received more years of formal instruction demonstrated less expertlike views about physics, an overall trend consistent with the previously reported results on U.S. college students. However, the slight increases in student performance on CLASS at the 9th and 12th grade levels were two exceptions, suggesting the relation between physics instruction and student epistemological beliefs may be mediated by a number of nonpedagogically related factors, such as content, sequence, teaching pace, review opportunities and external motivation.

\section{ACKNOWLEDGMENTS}

We thank all the participating instructors and students for their generous cooperation. We also wish to thank Wendy K. Adams, Katherine K. Perkins, and Mike Hull for their insightful discussion. 
[1] D. Hammer, Two approaches to learning physics, Phys. Teach. 27, 664 (1989).

[2] D. Hammer, Epistemological beliefs in introductory physics, Cognit. Instr. 12, 151 (1994).

[3] A. Elby, Another reason that physics students learn by rote, Am. J. Phys. 67, S52 (1999).

[4] L. Lising and A. Elby, The impact of epistemology on learning: A case study from introductory physics, Am. J. Phys. 73, 372 (2005).

[5] K. Gray, W. Adams, C. Wieman, and K. Perkins, Students know what physicists believe, but they don't agree: A study using the CLASS survey, Phys. Rev. ST Phys. Educ. Res. 4, 1 (2008).

[6] G. Kortemeyer, Correlations between student discussion behavior, attitudes, and learning, Phys. Rev. ST Phys. Educ. Res. 3, 010101 (2007).

[7] D. Hammer and A. Elby, Tapping epistemological resources for learning physics, J. Learn. Sci. 12, 53 (2003).

[8] B. Hofer and P. Pintrich, The development of epistemological theories: Beliefs about knowledge and knowing and their relation to learning, Rev. Educ. Res. 67, 88 (1997).

[9] W. K. Adams, K. K. Perkins, N. S. Podolefsky, M. Dubson, N. D. Finkelstein, and C.E. Wieman, New instrument for measuring student beliefs about physics and learning physics: The Colorado Learning Attitudes about Science Survey, Phys. Rev. ST Phys. Educ. Res. 2, 010101 (2006).

[10] A. Elby, J. Frederiksen, C. Schwarz, and B. White, EBAPS: Epistemological Beliefs Assessment for Physical Sciences, in Proceedings of the American Educational Research Association, Chicago, 1997 [http://www2.physics.umd.edu/ elby/EBAPS/home.htm].

[11] E.F. Redish, J. M. Saul, and R. N. Steinberg, Student expectations in introductory physics, Am. J. Phys. 66, 212 (1998).

[12] I. A. Halloun, Views about science and physics achievement: The VASS story, in The Changing Role of Physics Departments in Modern Universities: Proceedings of the International Conference on Undergraduate Physics Education, edited by E.F. Redish and J.S. Rigden (American Institute of Physics Press, College Park, MD, 1997), pp. 605-613.

[13] M. Sahin, Effects of problem-based learning on university students' epistemological beliefs about physics and physics learning and conceptual understanding of Newtonian mechanics, J. Sci. Educ. Technol. 19, 266 (2010).

[14] E.F. Redish, Teaching Physics with the Physics Suite (John Wiley \& Sons, Hoboken, NJ, 2003).

[15] V. Akerson, F. Abd-El-Khalick, and N. Lederman, Influence of a reflective explicit activity-based approach on elementary teachers' conceptions of nature of science, J. Res. Sci. Teach. 37, 295 (2000).

[16] F. Abd-El-Khalick, Embedding nature of science instruction in preservice elementary science courses: Abandoning scientism, but. .., J. Sci. Teach. Educ. 12, 215 (2001).

[17] F. Abd-El-Khalick, Developing deeper understanding of nature of science: The impact of a philosophy of science course on preservice science teachers' views and instructional planning, Int. J. Sci. Educ. 27, 15 (2005).

[18] V. K. Otero and K. Gray, Attitudinal gains across multiple universities using the Physics and Everyday Thinking curriculum, Phys. Rev. ST Phys. Educ. Res. 4, 1 (2008).
[19] F. Goldberg, S. Robinson, and V. K. Otero, Physics for Elementary Teachers (It's About Time, Armonk, NY, 2006).

[20] F. Goldberg, S. Robinson, and V. K. Otero, Physical Science and Everyday Thinking (It's About Time, Armonk, NY, 2008).

[21] D. Hestenes, Toward a modeling theory of physics instruction, Am. J. Phys. 55, 440 (1987).

[22] J. Jackson, L. Dukerich, and D. Hestenes, Modeling Instruction: An effective model for science education, Sci. Educat. 17, 10 (2008).

[23] E. Brewe, L. H. Kramer and G. O'Brien, Modeling instruction: Positive attitudinal shifts in introductory physics measured with CLASS, Phys. Rev. ST Phys. Educ. Res. 5, 1 (2009).

[24] E.F. Redish and D. Hammer, Reinventing college physics for biologists: Explicating an epistemological curriculum, Am. J. Phys. 77, 629 (2009).

[25] L. C. McDermott (Physics Education Group at University of Washington), Physics by Inquiry (John Wiley \& Sons, New York, 1996).

[26] B. Lindsey, L. Hsu, H. Sadaghiani, J. Taylor, and K. Cummings, Positive attitudinal shifts with the physics by inquiry curriculum across multiple implementations, Phys. Rev. ST Phys. Educ. Res. 8, 1 (2012).

[27] M. Milner-Bolotin, T. Antimirova, A. Noack, and A. Petrov, Attitudes about science and conceptual physics learning in university introductory physics courses, Phys. Rev. ST Phys. Educ. Res. 7, 1 (2011).

[28] S. Bates, R. Galloway, C. Loptson, and K. Slaughter, How attitudes and beliefs about physics change from high school to faculty, Phys. Rev. ST Phys. Educ. Res. 7, 1 (2011).

[29] M. Bowles and C. Stansfield, A practical Guide to Standards-Based Assessment in the Native Language (University of Illinois at Urbana-Champaign, Urbana, IL, 2008).

[30] K. Geisinger, Cross-cultural normative assessment: Translation and adaptation issues influencing the normative interpretation of assessment instruments, Psychol. Assess. 6, 304 (1994).

[31] V. Sawtelle, E. Brewe, and L. H. Kramer, Validation study of the Colorado Learning Attitudes about Science Survey at a Hispanic-serving institution, Phys. Rev. ST Phys. Educ. Res. 5, 1 (2009).

[32] L. Ding, N. W. Reay, A. Lee, and L. Bao, Are we asking the right questions? Validating clicker question sequences by student interviews, Am. J. Phys. 77, 643 (2009).

[33] Wendy Adams and Katherine Perkins (private communication).

[34] L. Ding, N. W. Reay, A. Lee, and L. Bao, Effects of testing conditions on conceptual survey results, Phys. Rev. ST Phys. Educ. Res. 4, 1 (2008).

[35] L. Ding and X. Liu, Getting Started with Quantitative Methods in Physics Education Research, in Getting Started in PER-Reviews in PER, edited by C. Henderson and K. A. Harper (American Association of Physics Teachers, College Park, MD, 2012), http:// www.per-central.org/items/detail.cfm?ID=12601.

[36] Q. Peng, Innovation, practice, and exploration: An introduction to standardized science curriculum-Physics, Phys. Bull. 2002, 18 (2002). 